\title{
Active Learning dalam Pembelajaran Akuntansi di SMA/SMK
}

\author{
Setyarini Santosa1), Ika Pratiwi Simbolon ${ }^{2)}$ \& Vita Elisa Fitriana ${ }^{3)}$ \\ 1)Universitas Presiden, setyarinis@president.ac.id \\ 2) Universitas Presiden, ika.pratiwi@president.ac.id \\ 3)Universitas Presiden, vita.elisa@president.ac.id
}

\begin{abstract}
ABSTRAK
Perkembangan teknologi memberikan dampak yang besar dalam dunia bisnis, seperti munculnya perusahaan-perusahaan berbasis teknologi. Perubahan tersebut juga mendorong adanya penyesuaian dalam penerapan maupun bidang keilmuan akuntansi. Oleh karena itu, pendidik diharapkan dapat menyampaikan ilmu akuntansi dari segi konsep maupun penerapannya dalam proses bisnis perusahaan. Untuk membantu penguasaan keterampilan ilmu akuntansi, pendidik dapat menggunakan metode pengajaran berupa active learning yang memusatkan aktivitas kelas dalam partisipasi aktif masing-masing siswa. Tujuan dalam kegiatan ini adalah peserta pelatihan mampu menerapkan metode active learning yang tepat dalam materi-materi pembelajaran akuntansi di SMA/SMK. Dalam pelaksanaan pelatihan, tiap-tiap peserta diajak untuk berdiskusi dan mencoba menerapkan metode active learning. Selain itu, juga ditampilkan data terkait efektivitas pembelajaran active learning yang ditunjukkan melalui peningkatan pemahaman siswa atas materi yang diajarkan. Pembahasan metode active learning dalam kegiatan ini memberikan ide-ide baru pada peserta untuk menyampaikan materi pelajaran dengan lebih bervariasi.
\end{abstract}

Kata-kata Kunci: Active Learning, Ilmu Akuntansi, Teknologi

\begin{abstract}
Technological developments have a major impact on world businesses, such as technology-based companies. These changes also encourage for several adjustment in accounting scope. Therefore, educators are expected to be able to convey accounting knowledge in terms of its application concept in company business processes. To help delivering accounting skills, educators can use management methods in the form of active learning that focuses class activities in the active participation of each student. The purpose of this activity is for training educators to be able to apply appropriate active learning methods in accounting learning materials at SMA/SMK. When the training was conducted, each participant is invited to discuss and try to apply active learning methods. In addition, presenter also explain the data about effectiveness of active learning implementation which is shown through increasing students' understanding of the material being taught. At the end, discussions and trainings of active learning methods could provide new ideas for participants to deliver more varied subject matter.
\end{abstract}

Keywords: Active Learning, Accounting, Technology

\section{PENDAHULUAN}

Sebagai bidang ilmu yang dikembangkan dari praktek perdagangan dan pencatatan/pembukuan sehari-hari, maka penguasaan keterampilan dalam menyusun laporan keuangan merupakan tahap awal proses belajar dalam ilmu akuntansi. Seiring dengan penguasaan keterampilan teknis penyusunan laporan keuangan, konsep atau teori akan diberikan tahap demi tahap sehingga pada tingkat belajar yang lebih tinggi, peserta didik dapat memahami akuntansi secara konseptual. Konsep atau teori akuntansi tetap harus dikuasai karena akan sangat berguna untuk dasar pemecahan masalah dalam praktek sehari-hari yang semakin kompleks. Kompleksitas tersebut didorong oleh 
perkembangan bisnis, situasi ekonomi maupun perkembangan teknologi dan informasi yang amat cepat dan dinamis.

Perkembangan teknologi memberikan tantangan cukup besar pada profesi akuntansi, baik di level keterampilan maupun konseptual. Keterampilan dalam proses akuntansi sangat dipengaruhi oleh hadirnya teknologi komputer. Sebagian besar perusahaan telah menggunakan komputer di dalam proses bisnisnya, termasuk dalam aspek akuntansi dan keuangan. Di tataran konsep, hadirnya perusahaan berbasis teknologi seperti gojek, tokopedia serta perkembangan financial technologi (fintech), memberi tantangan tersendiri pada bidang akuntansi. Salah satu tantangan tersebut berupa penentuan perlakuan akuntansi dalam pencatatan transaksi pada perusahaan yang menggunakan adopsi teknologi. Teknologi komputer dan informasi yang dulunya hanya merupakan faktor pendukung (infrastruktur) bisnis, saat ini telah menjadi faktor penentu utama dalam bisnis. Tanpa adanya teknologi, perusahaan-perusahaan modern seperti online stores, gojek dan sebagainya tidak dapat lagi beroperasi.

Hal ini menjadi tantangan tersendiri bagi dunia pendidikan akuntansi. Bagi sebagian besar siswa dan mahasiswa, terlepas dari adanya perkembangan teknologi dan informasi, siklus akuntansi cukup sulit untuk dipahami dan butuh banyak latihan untuk menguasai keterampilan dan konsep. Untuk itu pendidik harus mampu melakukan metode pembelajaran yang membuat siswa senang dan sekaligus tertantang untuk dapat memiliki pemahaman, keterampilan dan konsep akuntansi.

Sementara itu, di bidang pendidikan sendiri, telah disepakati bersama bahwa pendekatan student centered learning menjadi suatu alternatif pembelajaran yang akomodatif terhadap perkembangan jaman dan kebutuhan siswa atau mahasiswa. Peran guru dan dosen berubah menjadi fasilitator dan siswa atau mahasiswa menjadi lebih aktif dalam proses belajar mengajar. Pelatihan ini akan membahas implementasi active learning dalam pembelajaran akuntansi di tingkat SMA/SMK. Dengan dilaksanakannya kegiatan ini, diharapkan agar peserta pelatihan mampu menerapkan metode active learning yang tepat dalam materi-materi pembelajaran akuntansi di SMA/SMK.

\section{METODE PELAKSANAAN KEGIATAN}

\subsection{Peserta, Lokasi dan Waktu Kegiatan}

Peserta kegiatan PKM ini adalah guru SMK/SMA berjumlah 9 orang (lihat Gambar 1), dilaksanakan di Kampus Universitas Presiden, Jababeka Educational Park, Bekasi, pada Rabu, 26 September 2018. 


\section{DAFTAR HADIR PESERTA}

PELATIHAN BAGI GURU SMA/SMK DI WILAYAH CIKARANG 2018

"Penerapan Active Learning dalam Pembelajaran Ilmu Ekonomi dan Akuntansi di SMA/SMK"

President University, 26 September 2018

\begin{tabular}{|c|c|c|c|}
\hline No & Nama & Sekolah & Tanda Tangan \\
\hline 1 & Surjati Soenarjo., S.E. & SMA Don Bosco III & \\
\hline 2 & Supraptini, S.E. & SMA Presiden & \\
\hline 3 & Dra. Leni Hendrayani, MARS & SMK Al-Muthmainah & \\
\hline 4 & Vina Rosalina, S.Pd & $\begin{array}{l}\text { SMK Negeri } 1 \text { Cikarang } \\
\text { Utara }\end{array}$ & \\
\hline 5 & Ruhayati, S.E. & SMK Al-Muthmainah & \\
\hline 6 & Kiki Widhia Swara, S.Pd & $\begin{array}{l}\text { SMKS Mitra Industri } \\
\text { MM2100 }\end{array}$ & \\
\hline 7 & Aida Mardiyati, S.E. & SMK Boedi Luhur & \\
\hline 8 & Leti Erlita Tafiani, S.E. & SMKS Garuda Nusantara & \\
\hline 9 & Tri Santi Indah. S., S.Pd, M.Pd & sMk Negeri I Cikut & \\
\hline 10 & $(085692224955)$ & & \\
\hline 11 & & & \\
\hline 12 & & & \\
\hline
\end{tabular}

Gambar 1.

Peserta Kegiatan Pelatihan

\subsection{Tahapan Pelaksanaan Kegiatan}

Tahapan pelaksanaan kegiatan adalah sebagai berikut:

1. Koordinasi dengan LRPM Universitas Presiden

Kegiatan ini merupakan salah satu kegiatan serial enam jenis pelatihan untuk guru SMK/SMA dan yang sederajad yang diselenggarakan oleh LRPM Universitas Presiden bekerja sama dengan Jababeka Infrastruktur dan Kantor Perwakilan Dinas Pendidikan Provinsi Jawa Barat Wilayah 3 (lihat Lampiran 1). Rangkaian pelatihan guru ini diselenggarakan pada kurun waktu Agustus - November 2018.

\section{Persiapan Materi}

Pertama, dilakukan survei untuk melihat kurikulum dan silabus mata pelajaran akuntansi di SMK/SMAMencari sumber-sumber pengajaran berbasis active learning. Selanjutnya, dilakukan brainstorming untuk menyusun ide pelaksanaan active learning 
pada materi pelajaran akuntansi. Tahap terakhir, sharing implementasi active learning yang telah dilakukan langsung pada siswa-siswi SMK sebelum pelatihan untuk guru dilakukan.

\section{Pelaksanaan Kegiatan Pelatihan}

Pelaksanaan kegiatan dilakukan dengan cara presentasi dan praktek langsung beberapa materi dan penggunaan metode active learning yang tepat (Gambar 2). Diskusi dengan peserta dilakukan untuk mendapatkan tingkat keterterapan metode active learning pada kelas yang diasuh oleh tiap peserta di sekolah masing-masing.

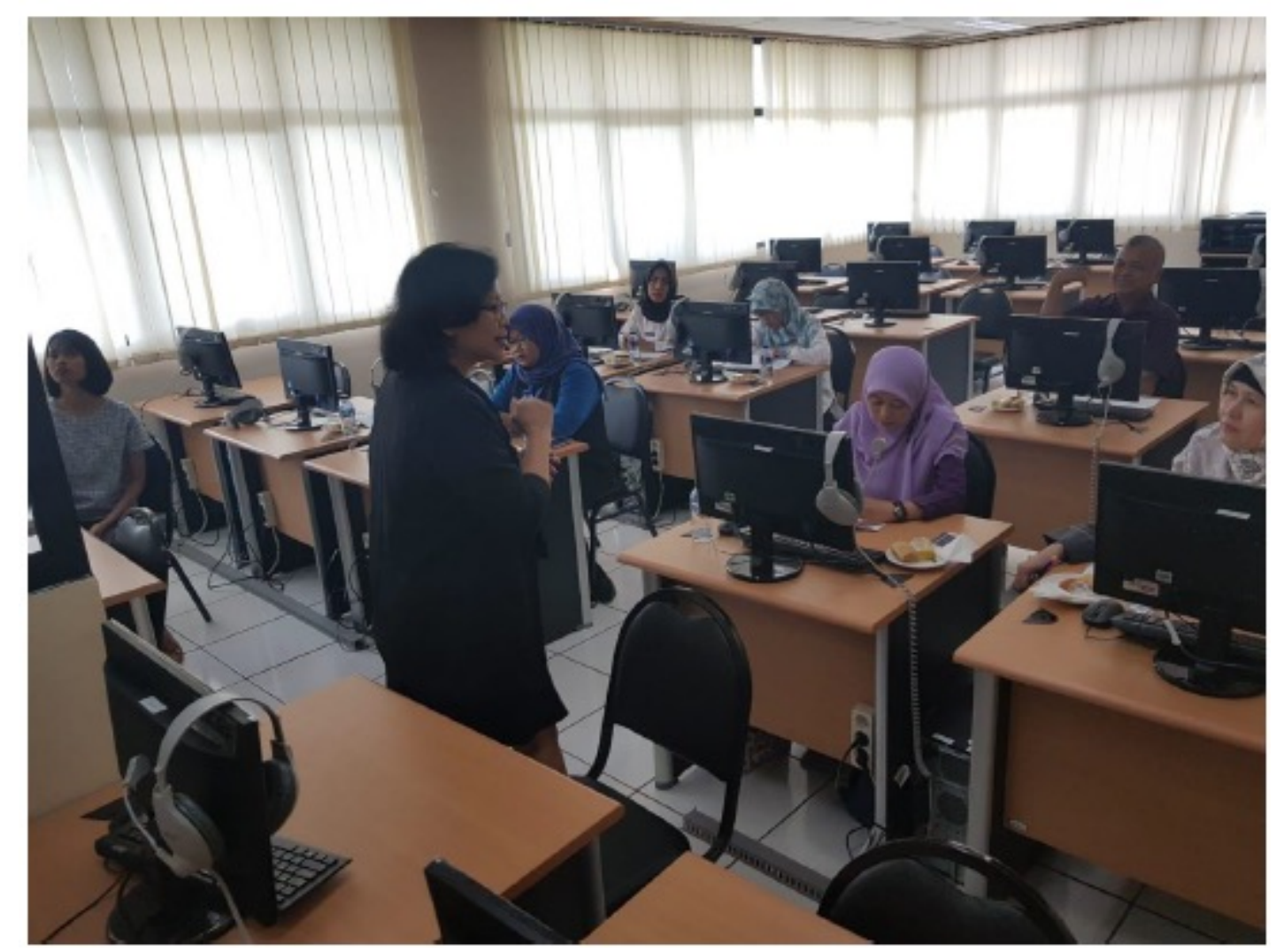

Gambar 2

Foto Pelaksanaan Kegiatan

\section{HASIL DAN PEMBAHASAN}

Kegiatan proses belajar mengajar active learning memerlukan keterlibatan anak dalam mempelajari sesuatu (Kariadi \& Suprapto, 2018). Lebih lanjut dijelaskan, ketika proses belajar active learning ini dapat diterapkan dengan baik, semakin kuat pula stimulus dan respon siswa dalam pembelajaran (Kariadi \& Suprapto, 2018).

Pelaksanaan kegiatan diawali dengan diskusi mengenai pengalaman menerapkan active learning atau pembelajaran yang tidak bersifat teacher-centered learning. Dari diskusi dengan peserta didapatkan informasi bahwa kegiatan pembelajaran aktual yang 
dapat dimasukkan dalam kriteria active learning hanya pembelajaran yang menggunakan tanya jawab setelah guru menjelaskan materi di depan kelas. Selain itu tipe pembelajaran lain yang dilakukan adalah membentuk kelompok kecil untuk mendorong terjadinya group discussion. Namun aktivitas dalam kelompok masih diserahkan kepada tiap-tiap kelompok. Guru tidak/belum memiliki desain yang terstruktur dan dapat digunakan sebagai panduan siswa untuk cara berdiskusi.

Kemudian, peserta diajak mempraktekkan beberapa strategi active learning dengan mengambil beberapa contoh materi yang ada dalam kurikulum. Setelah itu peserta akan diajak untuk berdiskusi dan mencari ide strategi active learning lainnya pada materi akuntansi lainnya. Dengan demikian peserta akan saling memperkaya ide pembelajaran dan dapat diterapkan di sekolah masing-masing.

Tabel 1 menunjukkan daftar materi active learning yang disampaikan dan didiskusikan dengan peserta kegiatan.

Tabel 1

Daftar Materi Active Learning

\begin{tabular}{|l|l|l|}
\hline No & Materi & Pendekatan \\
\hline $\mathbf{1}$ & Bentuk Badan Usaha & Jigsaw \\
\hline $\mathbf{2}$ & Jenis Perusahaan Menurut Bidang Usaha & Crossword Puzzle \\
\hline $\mathbf{3}$ & Elemen Laporan Keuangan & Metaplan \\
\hline \multirow{2}{*}{$\mathbf{4}$} & Persamaan Dasar Akuntansi & $\begin{array}{l}\text { One Minute Paper - Think } \\
\text { Pair Share - Muddiest } \\
\text { Point }\end{array}$ \\
\hline $\mathbf{5}$ & Skill - Persamaan Dasar Akuntansi & $\begin{array}{l}\text { Reciprocal } \\
\text { Strategy }\end{array}$ \\
\cline { 2 - 3 } & Menjurnal, Memposting & $\begin{array}{l}\text { Assembling Strip, Random } \\
\text { alphabet }\end{array}$ \\
\hline $\mathbf{6}$ & Pasar Modal & Board of Artwork \\
\hline $\mathbf{7}$ & Fungsi dan Jenis Uang & \\
\hline
\end{tabular}

Adapun alat dan bahan yang digunakan adalah:

1. Laptop

2. Proyektor

3. Mikrophone

4. Souvenir

5. Post-it notes

6. Kertas warna warni/origami

7. Papan Tulis

8. Spidol warna warni 
Peserta juga diajak untuk mencari ide-ide dan sumber-sumber pembelajaran active learning yang ada di youtube atau website lainnya. Dari sumber tersebut, peserta dapat memiliki referensi untuk mencari metode active learning yang paling tepat untuk materi tertentu yang hendak dibahas, sehingga dapat disesuaikan dengan besar kelas dan waktu yang tersedia. Beberapa alat atau bahan yang digunakan juga dimodifikasi sesuai dengan kebutuhan.

Peserta diajak menggunakan pendekatan metaplan, Kemudian setiap peserta diminta untuk melakukan simulasi kegiatan yang nantinya dapat mereka terapkan dalam proses belajar-mengajar di kelas. Untuk membuat proses pengajaran ini lebih menarik, peserta kegiatan juga diberikan beberapa cara modifikasi yang bersumber dari internet, seperti platform youtube.

Dalam pelaksanaan kegiatan ini juga dilakukan sharing kepada guru peserta atas pelaksanaan active learning yang telah diselenggarakan di SMK Dewantara 2 untuk siswa kelas $\mathrm{X}$ dan $\mathrm{XI}$ pada minggu sebelumnya. Materi yang diambil pada saat itu adalah materi tentang Elemen Laporan Keuangan dan materi tentang Pasar Modal, khususnya tentang valuasi saham.

Tabel 2.

Hasil Pre-test dan Post-test

Perbandingan Metode Konvensional dengan Active Learning

\begin{tabular}{|l|c|c|}
\hline \multicolumn{3}{|c|}{ Materi Laporan Keuangan } \\
\hline & $\begin{array}{c}\text { Konven- } \\
\text { sional }\end{array}$ & $\begin{array}{c}\text { Active } \\
\text { Learning }\end{array}$ \\
\hline Pre test & 48.57 & 41 \\
\hline Post tes & 53.93 & 57.67 \\
\hline Selisih & 5.36 & 16.67 \\
\hline Persentase & $11.03 \%$ & $40.65 \%$ \\
\hline
\end{tabular}

\begin{tabular}{|l|c|c|}
\hline \multicolumn{3}{|c|}{ Materi : Valuasi Saham } \\
\hline & $\begin{array}{c}\text { Konven- } \\
\text { sional }\end{array}$ & $\begin{array}{c}\text { Active } \\
\text { Learning }\end{array}$ \\
\hline Pre test & 50 & 50.3 \\
\hline Post tes & 66.43 & 76.67 \\
\hline Selisih & 16.43 & 26.37 \\
\hline Persentase & $32.86 \%$ & $52.42 \%$ \\
\hline
\end{tabular}

\section{KESIMPULAN}

Dari kegiatan pelatihan ini dapat disimpulkan bahwa kegiatan ini dapat memberikan ide-ide baru pada peserta untuk dapat melakukan variasi pengajaran active learning yang pada intinya merupakan bagian dari pengajaran untuk student-centered learning. Selian itu, kreatifitas guru dalam merancang metode pembelajaran active learning sangat diperlukan.

Mengingat besarnya manfaat kegiatan pelatihan ini, maka dapat disusun beberapa usulan untuk kegiatan selanjutnya, antara lain:

1. Melakukan kegiatan yang sama dengan target langsung pada siswa SMK/SMA. Kemudian dilakukan evaluasi lebih terstruktur terhadap siswa. 
2. Mengatur waktu pelaksanaan kegiatan pelatihan active learning untuk guru yang sesuai dengan jadwal SMK/SMA target agar jumlah peserta yang hadir lebih banyak.

\section{REFERENSI}

Keputusan Direktur Jendral Pendidikan Dasar dan Menengah No: 330/D.D5/KEP/KR/2017 tentang Kompetensi Inti dan Kompetensi Dasar Mata Pelajaran Muatan Nasional (A), Muatan Kewilayahan (B), Dasar Bidang Keahlian (C1), Dasar Program Keahlian (C2) dan Kompetensi Keahlian (C3).

Endarta, (2017). Struktur Kurikulum 2017. Diunduh dari:

http://duniapendidikan.putrautama.id/struktur-kurikulum-smk-2017/

Hartono, (2008). Strategi Pembelajaran Active Learning. Diunduh dari: https://sditalqalam.wordpress.com/2008/01/09/strategi-pembelajaran-activelearning/

Kariadi, D., \& Suprapto, W. (2018). Model Pembelajaran Active Learning dengan Strategi Pengajuan Pertanyaan untuk Meningkatkan Kualitas Proses Pembelajaran PKn. Jurnal Educatio, 12(1), 10-21.

Pujianto, A. (2013). Download Silabus Ekonomi dan Akuntansi Kurikulum 2013. Diunduh dari: http://www.akuntansipendidik.com/2013/08/download-silabus-ekonomi-danakuntansi-kurikulum-2013.html).

Rukmini, E. (20080. Deskripsi Singkat Revisi Taksonomi Bloom, Jurnal Majalah IImiah Pembelajaran. 2. 
Academics in Action Journal

Volume 3, Number 1, 2021, 23--30

\section{Lampiran 1. \\ Surat Undangan}

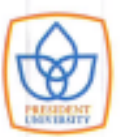

\section{PRESIDENT UNIVERSITY}

No.: 30/L.RPM/VII/2018

Kepada Yth.

Bapak Kepala Sekolab

Di tempat

Perihal: Undangan

Dengan bormat,

Dalam rangka meningkarkan perannya dalam pengembangan kualitas sumber daya masyaraka1 disekitarnya, Universitas Presiden bersams dengan P.T. Jahnbeka Infrastruktur dan didukung oleh Kantor Perwakilan Dinas Pendidikan Provinsi Jawa Barat Wilayah 3, bermaksud menyelenggarakan 6 jenis pelatihan bagi guru SMA/SMK/yang sederajat pada tahun 2018 ini.

Olch karena itu, karni mengundang partisipasi bapak dengan meogirimkan bapakibu guru terkait dari sekolah yang bapak/ibu pimpin untuk mengikuti pelatihan sebagaimana terlampir.

Untuk pendaftaran dan informasi lebih lanjut, kami persilahkan menghubungi:

1. Sdr. Tiara: 087840744707

2. Sdr. Ivena: 082260095358

atsu menuliskan email ke lrpmpu@ipresident.ac.id

Demikian. atas perhatian dan kerjasamanya kami ucapkan terima kasih.

Cikarang, 25 Juli 2018

Lembaga Riset dan

Pengabdian kepada Masyarakat

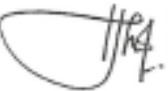

Dr. Ir. Farida Komalasari, Misti.

Direktur

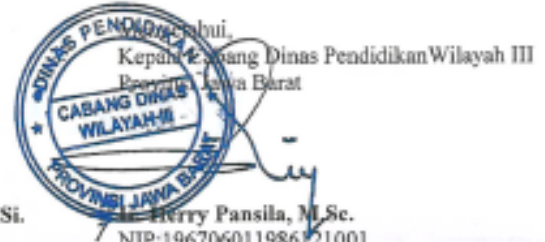

Tembusan:

1. Rektor dan Para Wakil Rektor Universitas Presiden

2. Direktur PT. Jababeka Infrastruktur 